\title{
A four-step model for diagnosing knowledge transfer challenges from operations into engineering design
}

Souza da Conceição, Carolina; Broberg, Ole; Paravizo, Esdras; Jensen, Anna Rose Vagn

Published in:

International Journal of Industrial Ergonomics

Link to article, DOI:

10.1016/j.ergon.2018.11.005

Publication date:

2019

Document Version

Peer reviewed version

Link back to DTU Orbit

Citation (APA):

Souza da Conceição, C., Broberg, O., Paravizo, E., \& Jensen, A. R. V. (2019). A four-step model for diagnosing knowledge transfer challenges from operations into engineering design. International Journal of Industrial Ergonomics, 69, 163-172. https://doi.org/10.1016/j.ergon.2018.11.005

\section{General rights}

Copyright and moral rights for the publications made accessible in the public portal are retained by the authors and/or other copyright owners and it is a condition of accessing publications that users recognise and abide by the legal requirements associated with these rights.

- Users may download and print one copy of any publication from the public portal for the purpose of private study or research.

- You may not further distribute the material or use it for any profit-making activity or commercial gain

- You may freely distribute the URL identifying the publication in the public portal 


\title{
A four-step model for diagnosing knowledge transfer challenges from operations into engineering design
}

\author{
Carolina Souza da Conceição ${ }^{\mathrm{a}} \bullet$ Ole Broberg $^{\mathrm{a}} \bullet$ Esdras Paravizo $^{\mathrm{b}} \bullet$ Anna Rose Jensen ${ }^{\mathrm{a}}$ \\ ${ }^{a}$ Department of Management Engineering, Technical University of Denmark, Produktionstorvet Building 424, DK 2800 Lyngby, Denmark. \\ ${ }^{\mathrm{b}}$ Department of Industrial Engineering, Federal University of São Carlos, Rod. Washington Luiz, km 235, 13565905 São Carlos, Brazil.
}

Knowledge gained from operations can help optimize the design of new installations in terms of system performance, health, and safety. Transferring such knowledge to engineering design teams makes it available for use in projects. However, the transfer involves different challenges. To better understand and identify these challenges, we combine a knowledge transfer model with a work systems model into the development of a conceptual four-step model for knowledge transfer from operations to engineering design. Knowledge transfer implies that the knowledge must be captured, transformed into an engineering design context, transferred to the appropriate individuals, and finally, applied to the design of new facilities. In this paper, we 1) present the development of this model, 2) illustrate its application in an empirical case study in an offshore oil company, and 3) propose a generic diagnostic tool to be applied in companies to diagnose and identify the existing challenges within knowledge transfer from operations to engineering design.

Relevance to industry: The proposed diagnostic tool allows for better understanding of design problems to be faced and for developing design solutions that improve health, safety, and production effectiveness, benefiting knowledge management and engineering design professionals in the offshore and maritime industries.

Keywords: Operations knowledge; engineering design projects; oil and maritime industry

\section{Highlights}

- A conceptual model combining knowledge transfer and work systems models.

- The key challenges in transferring operational knowledge to engineering design.

- A diagnostic tool for knowledge transfer systems in companies.

Declaration of interest: none.

Corresponding author:

Carolina Souza da Conceição

casou@dtu.dk

+4545255636 


\section{Introduction}

Many problems can be faced during operations of an offshore oil rig since operating conditions can change daily due to the environment, the oil well condition, equipment maintenance, and so on. Thus, how can we focus on the solutions to such problems not only when they happen but also in trying to prevent similar problems in future units? Although the prevention approach may sound simple or even like the obvious thing to do, generating qualified knowledge from rig operations and applying it in new projects is not a trivial task, and there are still several challenges regarding this knowledge transfer (KT) (Lurås et al., 2015; Vianello and Ahmed, 2012; Wulff et al., 1999a, 1999b).

The need for KT is especially the case for part of the offshore oil industry and in the wider perspective of the maritime sector. One of the main characteristics of engineering design in this industry is the complex nature of the product and its high hazard context. In this sector, engineering design is carried out by many dispersed design teams, with a very different set of standards from the onshore installations ones, and a distinct geographical separation exists between the engineering design and operation of the rigs (Walker et al., 2014). Many engineering designers have not witnessed their part of the design in action because they rarely visit operating rigs. Due to this lack of operational experience and the minimal margins of error and tight timeframes that engineering designers are faced with in these projects, KT is the main source of practical knowledge and experience in developing the projects of new units (Pagenhart et al., 1998).

Knowledge of the specific conditions for successful KT within the offshore oil industry is limited, but it is acknowledged that offshore operations are a potential knowledge source to be exploited when attempting to optimize new and existing units in terms of cost, safety, and production effectiveness (Conceição et al., 2012; Johnsen, 2014; Mallam et al., 2015; Skepper et al., 2000). Engineering designers may need to learn from lessons of previous designs and systems, but it is paramount that this transfer process regarding use conditions is "made explicit, recorded and regularly checked,” so it forms a basis for design decisions (Hale et al., 2007). One of the issues in these design processes is the lack of knowledge, many times because some kinds of knowledge are not available to the design team. However, this lack of knowledge may also be because designers do not have access to the knowledge they need, even if it is available, meaning the channels for the knowledge to flow do not exist (Taylor, 2007).

The differences between offshore and onshore personnel, both geographical and workwise, reinforce the need for a KT system that overcomes these existing communication barriers. Therefore, in this paper, we have a double goal: to develop and test a conceptual KT model from operations to engineering design and to propose a diagnostic tool based on this model that addresses the existing challenges. This is done based on the theoretical background combined with an empirical investigation in a case company in the offshore oil sector. This paper is organized as follows. In Section 2, we present the overall research methodology with methods for data collection and analysis. In Section 3, we introduce the theoretical background for the study and the development of the conceptual model. Section 4 reports the results, presenting the developed model, its application in the case company, and the proposed diagnostic tool. In Section 5, we emphasize the contribution of the study and conclude by discussing implications for practitioners, the limitations, and further research.

\section{Methods}

The study was carried out as a case study over a two-year period, examining an offshore oil company. We investigated the transfer of knowledge between operations on offshore oil rigs and onshore engineering design as our unit of analysis. The overall organization of the offshore oil company we studied included two main divisions: operations and engineering design. For the operations, we focused on offshore oil rigs, and for engineering design, we focused on project teams working on the design of new rigs. The engineering design process within the company was a projectbased organization and collaboration with different external actors, such as suppliers and shipyards. The design process 
involved several engineering disciplines and comprised different phases from idea generation and commercial viability to detailed design and construction, lasting over two years.

The study was completed in three overall steps:

1. We developed a conceptual model of transfer of knowledge from operations to engineering design combining insight from the case study with a conceptual analysis and combination of two previously disconnected research areas: KT and work systems models.

2. We tested this conceptual model in a case company, using the model to identify and systematize major challenges for KT.

3. We proposed a diagnostic tool for a KT system based on the use of the model and the identified challenges.

\subsection{Developing the Conceptual Model}

To improve KT and the application of operational knowledge in engineering design, it would be beneficial to obtain a more detailed understanding of the challenges and needs involved. We started with a literature review on the KT challenges in the specific field of the offshore oil industry, which led us to the need to understand better how the KT process is structured.

We investigated knowledge management literature (e.g., Frank and Ribeiro, 2014), with initial observations of the case company, to understand what was involved in the KT. Modeling the steps from the capture of rig workers' operational experiences to the application of this experience in the engineering design of new rigs would facilitate diagnosing the current KT situation in the case company and developing or modifying systems to improve KT. Furthermore, we investigated concepts regarding work systems (e.g., Horgen et al., 1999) to understand the characteristics of the senders and receivers of the knowledge to be transferred.

Making the connection between a work systems framework originating from human factors and the information systems field and the concepts from the knowledge management field turned out to be productive. We pragmatically applied a simple model of KT and considered the transfer as taking place between two work systems. We decided to do a more thorough analysis that could help model the transfer of knowledge from operations to engineering design projects.

\subsection{Testing the Model on an Empirical Case}

We started by collecting empirical data at the case company using interviews, in-situ observations, and workshops. The initial data were collected through interviews aimed at gaining a deeper understanding of the existing KT between operations and engineering design and the challenges inherent to it. Hence, the 54 interviewees were selected from organizational units and functions that had a role in the transfer (Table 1). These interviews were conducted over a period of one and a half years starting from the beginning of the project with the development of the conceptual model. 
Table 1 Interviewees from different divisions and work positions.

\begin{tabular}{lll}
\hline Division & Participants & Number \\
\hline \multirow{4}{*}{ Engineering design } & Project managers & 4 \\
\cline { 2 - 3 } & Project team members & 10 \\
\cline { 2 - 3 } & Specialists supporting the design teams & 4 \\
\cline { 2 - 3 } & Offshore personnel supporting the engineering design division & 4 \\
\hline \multirow{5}{*}{ Operations } & Performance team & 3 \\
\cline { 2 - 3 } & Asset/support onshore teams & 6 \\
\cline { 2 - 3 } & Rig shore base operations team & 4 \\
\cline { 2 - 3 } & Rig team & 19 \\
\hline
\end{tabular}

The interviews lasted between a half hour and one and half hours and were conducted by one to three researchers. They were semi-structured, supported by an interview guide with three overall themes: 1) current means for KT, 2) knowledge type, and 3) engineering design project organization. The questions were adjusted in relation to the organizational unit of which the interviewee was a part. The interview guide also evolved during the interview process from a more generic guide into one containing more specific and detailed questions, following our increased understanding of the KT process at the company.

The first theme was aimed at understanding the status of the KT at the case company. We investigated the sources of operational knowledge and the different channels and interactions used by the rig operators to share this knowledge and those used by the engineering design teams to retrieve it. By channels, we refer to ways of exchanging knowledge (e.g., phone calls, e-mail, meetings, information and communication technology (ICT) systems or other means).

The second theme was aimed at identifying the different types of knowledge shared by the rigs and needed by the engineering design teams during design projects for new rigs. Among the different types of knowledge we examined were 1) physical space issues, such as the general arrangement and position of equipment, 2) technical issues, such as equipment requirements and maintenance, 3) work processes, such as activity procedures and shift handover, 4) performance issues, such as workforce and downtime during production, 5) safety and risk issues, such as incidents, and 6) ideas for improvements. We focused on both practical and specific knowledge, such as issues regarding the need of storage space for large machinery leading to storage in unplanned spaces or regarding equipment that has more functionalities than necessary, leading to additional work hours for maintenance and unnecessary costs.

The third theme was aimed at mapping the project organization for the engineering design of new rigs. We investigated the different phases of the process and the different actors involved, including external participants, such as shipyards and suppliers. We also included the treatment of lessons learned from project to project and the interaction with offshore personnel during the new rig projects.

During the interview period, we also had the chance to do in-situ observations over two visits on an operating rig. The first visit lasted three days and happened one year after the start of the project. The second visit lasted five days and happened six months after the first one. In both visits, the main author and one more researcher observed the work onboard and interviewed operational personnel.

Later in the process, we conducted two workshops that lasted two hours each. The first workshop happened one and a half years after the start of the project and had five participants from engineering design. The goal was to identify the main channels for KT and the key challenges. We had two distinct activities where the participants had to draw a KT landscape and a design process grid using a game board and game pieces provided by the research group. The second workshop happened three months after the first one and had seven participants: two from operations and five from 
engineering design. The aim was to validate the challenges within the KT conceptual model and discuss possibilities for the diagnostic tool. We had one long activity where the participants had to simulate the knowledge flow starting from its capture on the rigs, using real cases collected during the rig visits. We used a large game board with the conceptual model and different game cards the participants used to point out challenges and suggestions for improvements.

The data were analyzed using a template analysis (Brooks et al., 2015) through an overall coding based on the KT model for the interviews and part of the discussions from the workshops. The analysis took place in parallel with the data collection, and four researchers worked on it. Three researchers read the interview transcripts, and one researcher read a subsample of the transcripts. We focused on understanding each step of the KT process and on identifying key challenges with the current KT systems. By reading the initial transcripts, detailed codes within the KT model emerged from the raw data and were used to analyze the full set of transcripts. The in-situ observations and the results from the workshops were used to consolidate the analysis from the transcripts. With the analysis, we could test the conceptual model using it throughout the process to identify and systematize the key challenges.

The codes helped us condense extensive raw textual data into a brief, summary format, structuring it based on four steps as part of the developed KT model:

1) the knowledge senders (field workers, supervisors, etc.) and the channels used to capture and document knowledge on the rigs;

2) the mechanisms used to filter and qualify knowledge in the systems, investigating whether the knowledge was mostly pushed (captured and registered) from the rigs or instead needed to be pulled (retrieved and asked for) by the design teams when needed;

3) the receivers of the knowledge (project team members, project managers, etc.) and the ways this knowledge was sent to or retrieved by the engineering design project teams, identifying the different transfer channels; and

4) the mechanisms for making use of operational knowledge in design projects, acknowledging the complex design process and its different participants.

\subsection{Proposing the Diagnostic Tool}

After using the conceptual KT model to systematize the findings from the empirical case and structure the existing challenges for KT in the case company, we proposed a diagnostic tool. This tool emerged from the developed KT model, the key challenges identified in the case company and the overall challenges reported in the literature. We attempted to generate specific yet generalizable questions that could help identify challenges and better understand the existing $\mathrm{KT}$ issues in different companies.

\section{Theoretical Background}

In this section, we first investigate the KT challenges within the offshore oil industry, reporting on previous studies presented in the literature. Next, we introduce and discuss the concepts and models of KT and work systems. As KT is a huge area of interest and the concept of knowledge is itself very disputed, we will start out by clarifying our approach using some fundamentals of knowledge, information, and the transfer process.

\subsection{Knowledge Transfer Challenges in the Offshore Sector}

In geographically dispersed organizations, such as in the offshore oil industry, valuable knowledge can reside in different locations, and the ability to learn on the organizational level depends on the capability on KT and exchange 
processes (Nesheim and Gressgård, 2013). Having a focus on cross-organizational and departmental exchange of knowledge and experiences, Nesheim and Gressgård (2013) investigated which factors have a positive influence on knowledge sharing and how knowledge sharing has a positive effect on knowledge application. They presented indications of differences between offshore and onshore employees concerning factors influencing knowledge sharing, thus highlighting the importance to take notice of both onshore and offshore work practices and the differences that challenge or support KT and sharing. In developing capable knowledge systems, the difference in users of the systems must be considered to have a potential for transfer of knowledge.

Examining a safety management system in an oil and gas company, Wold and Laumann (2015) saw it as a sociotechnical system that contains different kinds of documentation and references and works to transfer knowledge by accumulating and spreading organizational experience. The authors highlighted some of the challenges and limitations of this system, which are common to other KT systems, such as 1) preference for face-to-face communication rather than ICT-based solutions to avoid misunderstandings, 2) vague descriptions leading to decreased use of the system, and 3) information overload with too many documents to examine and too much information provided.

Wulff et al. (1999a, 1999b) studied the implementation of ergonomic requirements in the design of offshore installations and highlighted both the importance of these requirements and, simultaneously, the difficulties and problems in implementing them. Challenges mentioned include the lack of knowledge on ergonomics and operational issues on the engineering design side and the format in which the knowledge and requirements are presented to the designers, which makes it difficult for them to understand the real problems and how to implement guidelines. In another paper reporting the same study, Wulff et al. (2000) highlighted yet another challenge: the huge amount of documentation and information common to large-scale engineering projects such as that seen in the offshore oil sector.

In another study on design in the offshore industry, Lurås et al. (2015) identified several challenges engineering designers face in this industry. Two are related to KT: 1) obstacles to gaining user insight and 2) the large amount of information to grasp. Gaining access to offshore workers and the rigs is pointed out as a major challenge, leading to the need to rely on secondary sources of information or written material. According to the interviewed designers, the available knowledge is fragmented, while its volume is substantial, and the authors stress the need for strategies to filter and structure this knowledge.

In a study of petroleum and gas companies, Ranjbarfard et al. (2014) pointed to several obstacles to setting up efficient KT processes, among which are lack of technical support for integrated technology to enable use of knowledge management tools, lack of an appropriate structure for bringing individuals into the KT process, and lack of alignment between critical knowledge and organizational goals.

In a study done on the oil industry, Vianello and Ahmed (2012) stated that "a systematic transfer of knowledge from previous rigs to engineering designers involved in the development of new rigs is crucial to avoid recurrent problems.” In their study, the authors found that no systematic transfer of operational experience to engineering design was occurring. Furthermore, they noted that any knowledge captured from the rigs in the form of documentation and pushed into knowledge systems was not necessarily reused on the engineering design side. In another paper from the same study, Ahmed-Kristensen and Vianello (2015) argued that "although engineering designers found knowledge about changes, issues and improvements relevant for the design phase, they rarely retrieved available documentation from the knowledge repositories, instead preferring to contact directly senior positions at the operational site if necessary.” Their findings highlight the need to translate and structure knowledge in a way that addresses the needs of the engineering designers for such knowledge to be successfully shared.

In line with the different challenges reported in the literature, Kjellén (2007) proposed an idealized model of how operational feedback to design can be secured (Figure 1), accounting for both formal and informal channels of 
communication: written or person-to-person contact. He highlighted the importance of knowledge carriers (such as technical specifications or checklists) and arenas for knowledge exchange (such as meeting places for design verification) for the transfer and integration of ergonomic knowledge into design.

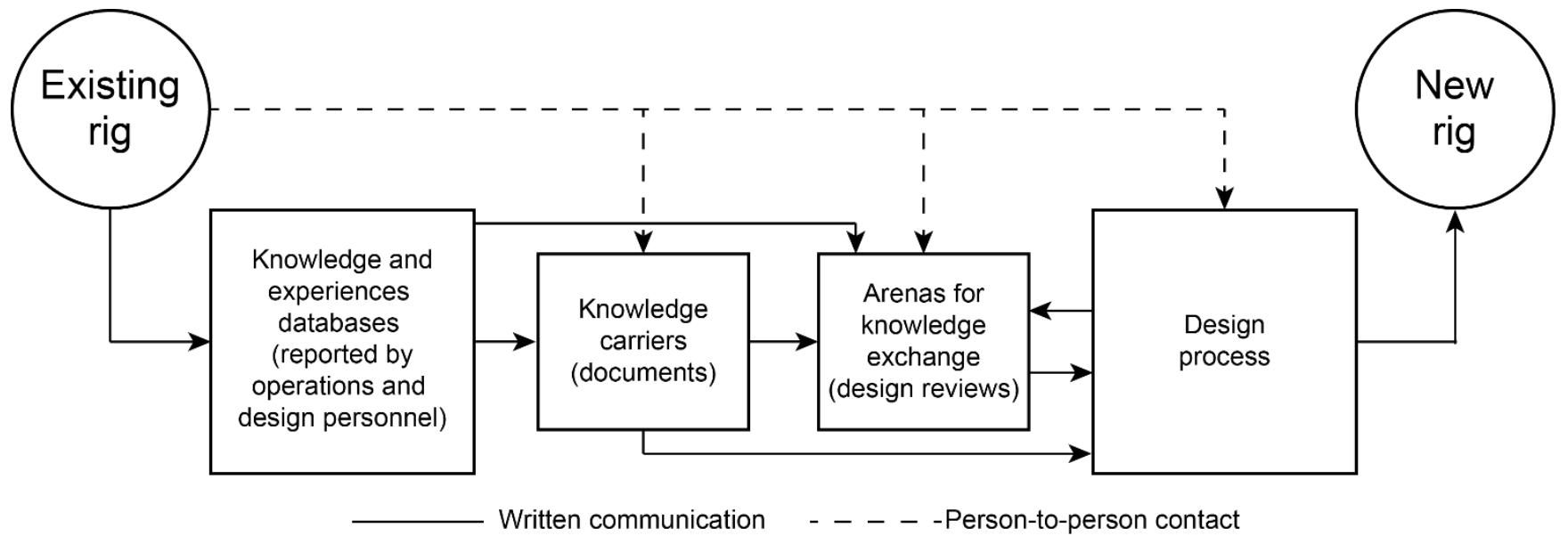

Figure 1 Idealized model for knowledge transfer from operations to design (adapted from Kjellén, 2007).

\subsection{Knowledge Transfer Models}

The concept of knowledge is a contentious one, and several definitions can be found in the literature. Although this discussion is outside the scope of this study, a distinction between information and knowledge may be useful when studying KT. Dixon (2000) linked the term 'knowledge' to 'action' to distinguish it from the term 'information.' Information may be defined as data that has been sorted, analyzed, and displayed, and which is communicated through spoken language, graphic displays, or numeric tables. In contrast, Dixon defined knowledge as "the meaningful links people make in their minds between information and its application in action in a specific setting” (Dixon 2000, p. 13).

The basic idea behind KT is often illustrated using a sender and receiver. In a communication-based view, KT is regarded as a message encoded in a medium by a sender and sent through a channel to a receiver within a given context (Yakhlef, 2007). This framework is based on the Shannon-Weaver model of communication (Shannon, 1948). Though it has been criticized, the model is illustrative, as it points out the basic elements of KT (i.e., the sender, message, channel, and receiver). These terms seem to be applied within KT models across different theoretical starting points, even if they erode the distinction between knowledge and information. In developing our model of KT, we draw on literature spanning the distinctions between knowledge and information. Hence, both terms appear in the following sections.

Frank and Ribeiro (2014) reviewed and compared 14 KT models. They proposed two overall approaches to KT: the engineering approach and emergent approach. This distinction can be considered an unfolded version of the work of McMahon et al. (2004), who suggested a codification approach and a personalization approach based on the work of Hansen et al. (1999). The 14 KT models reviewed by Frank and Ribeiro (2014) share the idea that KT is a process that can be divided into several phases. The nomenclature and number of phases differ from model to model. Frank and Ribeiro (2014) proposed a new KT model with the following five phases: knowledge generation, identification, processing, dissemination, and application.

We also approach KT as a process. When starting the investigation of the case company, we applied an initial KT model based on preliminary readings of the knowledge management literature, predominantly based on the engineering approach (Figure 2). We consider that KT implies that the knowledge must be captured on the rigs, transformed into 
an engineering design context, transferred to the appropriate engineering design project team members, and finally, applied along with the design process for new rigs. It is thus proposed that KT is a process involving four activities: capture, transformation, transfer, and application (CTTA).

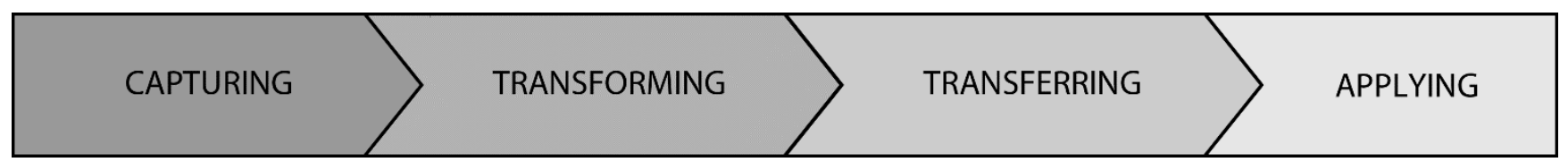

Figure 2 The CTTA knowledge transfer model.

This model was chosen for pragmatic reasons. First, we wanted to focus on KT between geographically dispersed groups of people, making it necessary to involve some formalization, codification, and use of ICT as transfer channels. Second, our model needed to be operational for a business environment, so we could specify whether and how to improve the current transfer of operational knowledge to engineering design. Third, it was well known in the company that personal interactions, and hence emergent KT, were a widespread mechanism. However, the company also realized the vulnerability of this form of KT, and they wanted to know more about how a more formal procedure could be implemented.

\subsection{Knowledge Transfer Processes}

In this section, we will introduce and discuss each step in the CTTA knowledge transfer model.

\subsubsection{Capturing knowledge}

Capturing indicates that the knowledge exists on the oil rigs, and that it just needs to be captured. However, capturing knowledge relevant to engineering design during rig operations is a complex process, including how the experiences of rig workers become knowledge that can be transferred to and easily understood by engineering designers. Dixon (2000, p.13) defined 'common knowledge' as "knowledge generated from the experience of people engaged in organisational tasks." Common knowledge is derived from action and carries with it the potential for others to use it to act. On an oil rig, knowledge generation or creation takes place when rig workers are engaged in organizational tasks (i.e., carrying out their work tasks). When part of this knowledge is formalized into a written document and packaged in a way that makes it compatible with an information system, it is captured.

\subsubsection{Transforming knowledge}

Transforming is seen differently between KT scholars. Mougin et al. (2015) proposed that, to become a knowledge object, the knowledge should be interpretable by a third party that did not participate in its construction. Frank and Ribeiro (2014) defined three activities that we consider to be transforming. First, the knowledge initially formalized and captured must be further explicated and embodied in formal documents. Second, the explicit knowledge is formulated to make it clearer for the receivers. Third, the explicit knowledge is consolidated, meaning that other sources of information are added that may enrich the knowledge (e.g., pictures). Hicks et al. (2002) pointed to the need for preprocessing to either formalize informal information or provide supplementary formal information to clarify the informal elements. Based on the offshore case, we suggest that transforming entails two processes. First, when a rig worker experiences a problem, he or she needs to be able to frame the problem as a design problem, meaning that the problem can be solved if the design is changed. Second, in line with Frank and Ribeiro (2014), the problem needs to be explicated as a design problem. 


\subsubsection{Transferring knowledge}

Transferring concerns 'circulating' the captured and transformed knowledge or making it available for other individuals and groups in the organization, in our case, the engineering designers of a new rig. This phase is also termed dissemination or distribution and involves creating and using channels and procedures to share and distribute stored knowledge (Frank and Ribeiro, 2014). The channels can be physical, such as paper documents, or virtual based on ICT (e.g., a knowledge management system). In the emergent approach, it is people who are the channels of dissemination through interactions with one another (Mougin et al., 2015; Yakhlef, 2007), or in our case, rig workers interacting with engineering designers in a project team.

\subsubsection{Applying knowledge}

Applying knowledge concerns the recipient taking in and using the transferred knowledge. Frank and Ribeiro (2014) identified three steps in this phase: 1) absorption and assimilation of the available knowledge, 2) knowledge application within a new project, and 3) integration and retention of the new knowledge in the work routines of the project team. The authors also stress that the transferred knowledge is now being applied in a new context that differs from the context in which knowledge was originally created (i.e., onboard an oil rig). When knowledge is being applied in a new context, this is a new knowledge creation activity, the outcome of which is dependent on the new context, in our case, the engineering design of oil rigs. Both the knowledge content and context are emergent outcomes of social interactions between individuals and groups.

\subsection{Work Systems Models}

It has been frequently stressed that KT entails two different contexts: the context of the sender and the context of the receiver. We began our case study pragmatically by conceptualizing the two contexts as two work systems with the operating oil rigs as one work system and the engineering design department as the other work system.

The notion of work systems has been put forward within different fields. From an information systems point of view, Alter (2008) defined a work system as "a system in which human participants and/or machines perform work (processes and activities) using information, technology, and other resources to produce specific products and/or services for specific internal or external customers." From a process architecture point of view, Horgen et al. (1999) defined a workplace in terms of a system model in which work practices are considered embedded in four interdependent elements: space, organization, finance, and technology (SOFT model; Figure 3). 


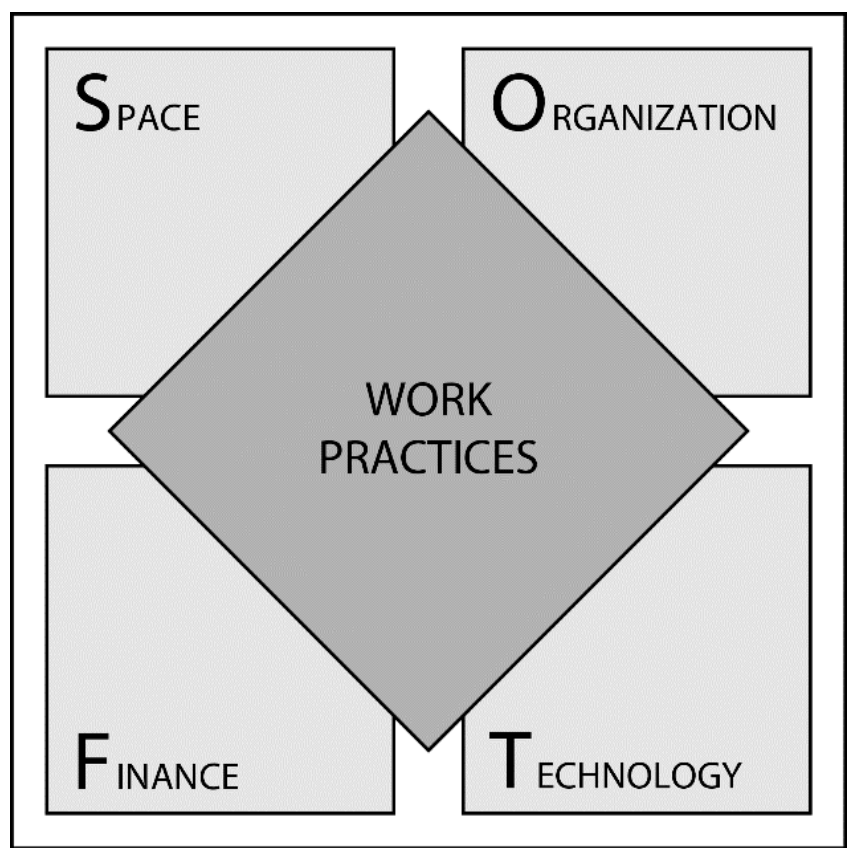

Figure 3 The SOFT system model (modified from Horgen et al., 1999).

Work systems are human constructs that help delimit what is in focus. To take a systems view, we need to set boundaries. When applying the concept of work systems to organizations, it often turns out that the organization must be defined as consisting of multiple work systems. The co-existence of work systems introduces challenges concerning alignment and coordination, and hence how the work systems interact (Alter, 2010). Alignment and coordination may be hampered by different system goals and performance indicators.

The two work systems of operations and engineering design have their own characteristics that might enable or hinder the transfer of operational knowledge. This can be assessed from the notion of capacity. Parent et al. (2007) suggested a KT system model that includes three capacities. In our case, the generative capacity is a characteristic of the offshore rig work system and refers to the ability to discover or improve knowledge. Disseminative capacity denotes "the ability to contextualise, format, adapt, translate and diffuse knowledge through a social and/or technological network and to build commitment from stakeholders" (Parent et al., 2007). The absorptive capacity is a characteristic of the engineering design work system and regards the ability to recognize the value of new external knowledge, assimilate it, and apply it to address relevant issues in the design of new rigs. The SOFT model helps in understanding and modeling the two complex contexts of the sender and the receiver. The model emphasizes the need to focus on actual work practices within the two systems, including practices in knowledge management.

\section{Results}

The empirical collected data provided us with an overall understanding of the current situation of KT at the case company and with insight on the entire process by which operational knowledge was transferred to the design process for new rigs and the challenges in this. According to one rig operator, "The end user is still the guy who has been stabilizing rigs for years and who can actually say by a quick look in the drawings: 'This is not going to work."' Thus, even before having the drawings, rig personnel can contribute knowledge that can save both time and costs associated with changes needed at later stages. The design engineers acknowledged the importance of operational knowledge, but as one engineer said, "Sometimes if you just hear that there is a problem, you don't really understand what kind of problem it is unless it is described well enough from operations for us (design engineers) to understand." 
In this section, we present our conceptual model for the transfer of knowledge from operations to engineering design. Based on the model, we test it on the case study and identify the key challenges for transferring knowledge, and afterwards, we propose a KT diagnostic tool.

\subsection{Four-step CTTA Knowledge Transfer Model}

By connecting the concepts of KT and work systems, we arrived at a model of KT between operations and engineering design (Figure 4).

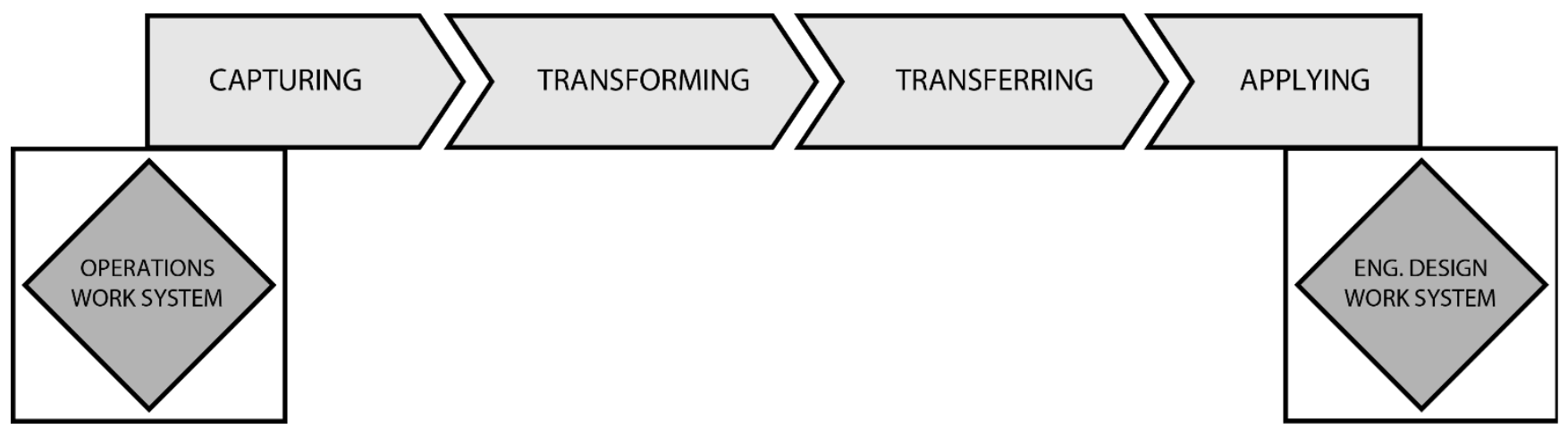

Figure 4 Conceptual four-step model of knowledge transfer from operations to engineering design.

Both work systems are characterized by the SOFT elements and their interactions. This is the context of the sender. The work system characteristics, including its KT capacities, will influence possibilities for and limitations of KT. Rig workers' operational experiences are captured in the operations work system, made ready for transfer, transferred to the engineering design work system through the capture-transform-transfer process steps, and then finally applied to a new design in the other work system.

\subsection{Applying the Four-step CTTA Model}

Mapping the existing KT channels helped us interpret and analyze the findings, allowing also to identify several issues related to the KT process. The company had different systems in place for transferring information from the rigs to the onshore headquarters (e.g., reporting safety incidents and equipment breakdowns). However, there was no dedicated system in place for capturing operational experiences that would be of importance when designing a new rig. Initially, we identified the different channels used for operational KT. Figure 5 shows a map of the existing formally established channels. However, most of the direct KT occurred through more informal channels, such as phone calls, e-mail, or meetings. 


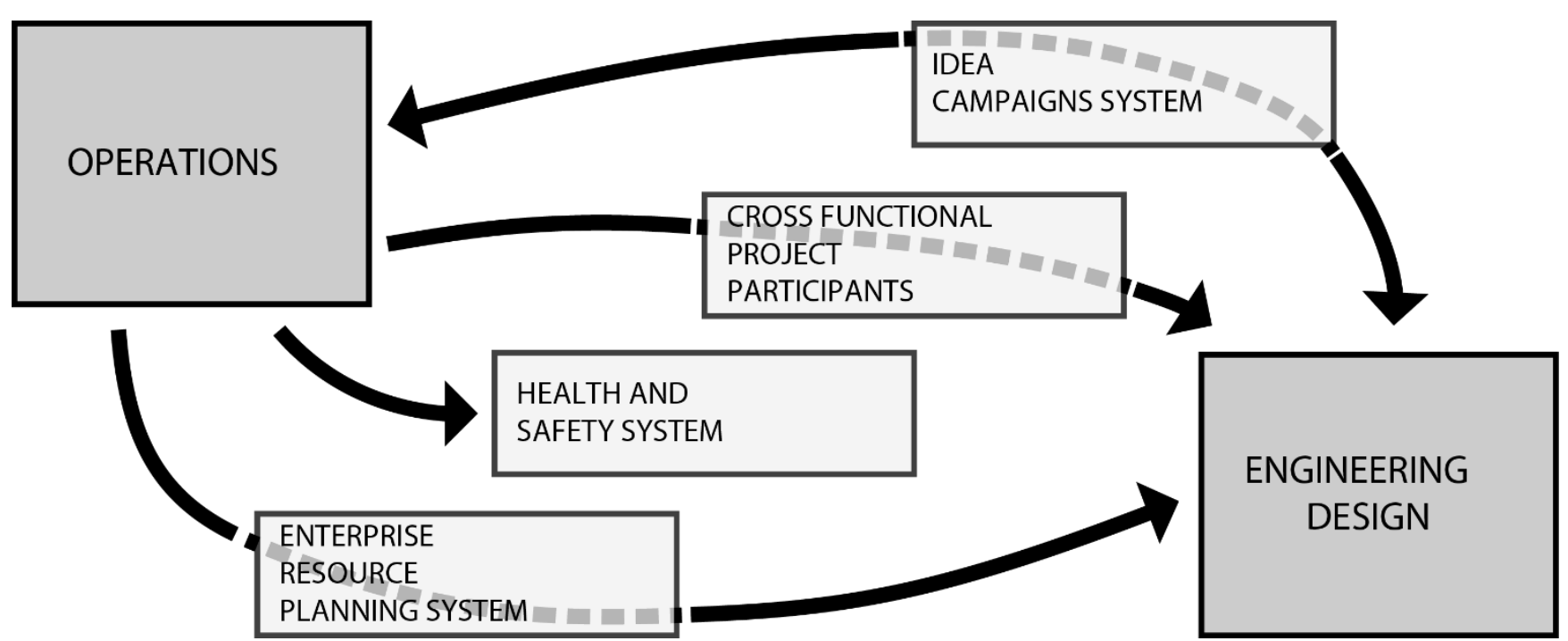

Figure 5 Formally stablished channels through which knowledge transfer occurred in the case company.

The enterprise resource planning system and the health and safety system were both used daily to register information ranging from work orders to incident reporting and ideas for improvements at different levels. However, the latter system was not being accessed by the engineering design division. The idea campaign system was specific for ideas for improving specific projects or themes, but it lacked dedicated personnel to handle and systematize the knowledge gathered in the system. Furthermore, the case company also had cross-functional project participants working as a KT channel. Those participants came from the rigs and participated in a specific project, bringing direct knowledge into the project, working as mediators to retrieve the knowledge that was needed.

We first used the mapping of the existing KT landscape and the interview and workshop coding to initially structure the findings. After, by also using the four-step CTTA model, we related all the issues identified with the different steps of the KT process, allowing us to correlate and restructure the findings into challenges. Table 2 summarizes the major challenges, which we will discuss in more detail in this section. These challenges were presented for the participants of the second workshop, who confirmed them all.

Table 2 Challenges identified for each step of the CTTA framework.

\begin{tabular}{ll}
\hline Knowledge Transfer Steps & Challenges \\
\hline Capturing knowledge on the rigs & $\begin{array}{l}\text { Captured knowledge is not targeted or oriented toward design } \\
\text { Different systems for capturing and retrieving knowledge are used } \\
\text { Key performance indicators do not encourage knowledge capture or transfer for design } \\
\text { purposes }\end{array}$ \\
\hline $\begin{array}{l}\text { Transforming captured } \\
\text { knowledge into knowledge } \\
\text { valuable for design }\end{array}$ & $\begin{array}{l}\text { Difficult to qualify captured knowledge due to the amount and complexity } \\
\text { Captured knowledge is not transformed for target design activities }\end{array}$ \\
\hline \multirow{2}{*}{$\begin{array}{l}\text { Systems are not configured to transform captured knowledge for design processes } \\
\text { project teams }\end{array}$} & $\begin{array}{l}\text { Lack of systems or management strategies to bring operational knowledge to the design } \\
\text { process } \\
\text { Difficult for the design team to search for and retrieve relevant knowledge } \\
\text { Transfer of knowledge relies on individuals and personal strategies }\end{array}$ \\
\hline $\begin{array}{l}\text { Applying operational knowledge } \\
\text { in the design of new rigs }\end{array}$ & $\begin{array}{l}\text { Difficult to integrate operational knowledge into design projects at the right time } \\
\text { Interaction with external actors may limit including operational knowledge } \\
\text { No formal transfer of learning and experience from project to project }\end{array}$ \\
\hline
\end{tabular}




\subsubsection{Capturing knowledge}

To manage the complexity of its operations, the case company employed several ICT systems, both onshore and offshore. The variety of existing systems, the types of knowledge registered in the systems, and the lack of focus on generating operational knowledge toward design are all issues related to how knowledge is captured on the rigs. It was acknowledged that operational knowledge is needed during engineering design; as a rig worker participating in the project team said, "The people sitting on the design team don't have a lot of operations knowledge because they are not in operations." Operational knowledge may make sense within the operations division but may not make sense or be considered valuable in the engineering design division. This is mainly because most of the operational knowledge registered in the systems was not categorized toward design, and there were no structured systems to process the captured knowledge.

One main challenge was related to having knowledge targeted for design purposes. This was connected to the challenge of not having specific performance indicators encouraging rig workers to focus beyond operations on capturing and registering this kind of knowledge. Another challenge was related to the consistency with which systems were used. The two divisions used different technologies, procedures, and systems to capture, store, and retrieve knowledge. As highlighted by the same rig worker, "There are a lot of systems, maybe too many, because you don't know where to start looking for things when you have so many databases." In addition, the lack of standards for how to formalize and package operational knowledge made it even harder to track and retrieve such knowledge.

\subsubsection{Transforming knowledge}

Since captured knowledge was not usually intended for design purposes and was not always seen as worth integrating into the design processes, other challenges emerged related to the need to transform the operational knowledge for design purposes. According to one design engineer, "The better it's described, the better we (the engineering designers) can make the functional specification, understanding what is the root cause of the problems." However, due to the amount and complexity of operational knowledge, challenges included 1) dealing with the large amount of data and knowledge registered in the systems when standards for formalizing and packaging this knowledge were not available and 2) filtering and qualifying the captured knowledge for design purposes.

A further challenge was related to the KT systems not having the functionality to transform captured knowledge into knowledge valuable for design, making it difficult for the design engineers to contextualize the knowledge found in the existing systems. There was an overload of knowledge available in the systems, leading to the discussion of whether extra functionalities in the systems would be sufficient or whether extra resources should be considered for this process. A rig worker participating in the project team suggested having "a core group that analyzes everything on a continual basis, developing concepts that we can then park and have ready to execute at the point we set a requirement specification."

\subsubsection{Transferring knowledge}

There was a large amount of knowledge from the rigs registered in the systems that could not be found by the design teams, who then needed to collect this knowledge by contacting the offshore personnel. Not having the knowledge contextualized and available for the engineering designers made it harder for the designers to retrieve the needed knowledge. The lack of a management strategy that provided tools for transferring knowledge from one division to the other was a major challenge related to the transfer of knowledge. This related to the challenge of it being difficult to access and retrieve the knowledge held in the systems.

Furthermore, the KT that did occur relied heavily on individuals or informal channels that were difficult to track, learn from, or utilize at an organizational level. As pointed out by an offshore section leader, "Quite often it is based on 
chance. You need to meet someone, talk to someone, rather than it being systemized, which I think is an issue.” The challenge was the primary use of personal strategies to get the knowledge transferred to the engineering designers. "There are ways to retrieve experiences or knowledge that can be relevant to improving operations, but that is more of an old boy's network, emailing, more informal," as highlighted by a project team member with offshore experience.

\subsubsection{Applying knowledge}

The last step of the KT process is the integration of the transferred knowledge into the design projects. The variety of actors in the design process and the lack of specific standards to structure the integration of operational knowledge into the design of new rigs led to different challenges. One of the challenges was that knowledge from the rigs was not necessarily available at the right time in the project cycle, meaning that the available knowledge was sometimes irrelevant or impossible to implement in terms of design specifications. As stated by a project team member with offshore experience, "If people are pulled in later in the phases and have some great ideas, we have to say that it is too late, we have already made the decisions; (...) but if we get these people in before we make decisions we can save time and [the knowledge] will be easier to implement."

Including knowledge from operations in new designs was also challenging and limited due to the complex project organization, in which external actors such as suppliers and shipyards played an influential role. Furthermore, since a formal process for KT from project to project was not in play, the process became highly dependent on a small number of designers who carried the knowledge with them from project to project. The challenge here was also in defining formal reviews of the design standards and specifications based on the knowledge transferred to guarantee that the knowledge would also be considered in future projects. "We need to improve projects that we already have on the shelf, so what we should do is make sure we evaluate and revisit them," as highlighted by an engineering design division member.

\subsection{Knowledge Transfer Diagnostic Tool}

The KT diagnostic tool was built based on the conceptual model and empirical insight gained from the case study of the offshore oil company. Posing questions is the character of the tool, which is intended to be used when a company wants to start improving the transfer of knowledge from operations to engineering design. By asking the right questions and diagnosing the status, the company will know more precisely what challenges must be overcome to improve the KT system and where to focus. Table 3 shows the KT diagnostic tool. 
Table 3 Knowledge transfer (KT) diagnostic tool.

\begin{tabular}{|c|c|c|c|c|c|}
\hline Rig Work System & Capturing & Transforming & Transferring & Applying & $\begin{array}{l}\text { Engineering } \\
\text { Design } \\
\text { Work System } \\
\end{array}$ \\
\hline $\begin{array}{l}\text { Who are the } \\
\text { employees and } \\
\text { what are their work } \\
\text { practices? How is } \\
\text { work organized and } \\
\text { what types of } \\
\text { technology support } \\
\text { it? }\end{array}$ & & & & & $\begin{array}{l}\text { Who are the } \\
\text { employees and } \\
\text { what are their work } \\
\text { practices? How is } \\
\text { work organized } \\
\text { and what types of } \\
\text { technology support } \\
\text { it? }\end{array}$ \\
\hline $\begin{array}{l}\text { What is the } \\
\text { generative } \\
\text { capacity? }\end{array}$ & $\begin{array}{l}\text { Which } \\
\text { procedures and } \\
\text { tools are used to } \\
\text { generate and } \\
\text { capture } \\
\text { experiences and } \\
\text { knowledge? }\end{array}$ & $\begin{array}{l}\text { How are relevant } \\
\text { experiences and } \\
\text { problems framed } \\
\text { as a design } \\
\text { issue? }\end{array}$ & $\begin{array}{l}\text { In what types of } \\
\text { channels is the } \\
\text { knowledge } \\
\text { circulated? }\end{array}$ & $\begin{array}{l}\text { How and to what } \\
\text { extent is the } \\
\text { transferred } \\
\text { knowledge applied } \\
\text { in the design } \\
\text { process? }\end{array}$ & $\begin{array}{l}\text { What is the } \\
\text { absorptive } \\
\text { capacity? }\end{array}$ \\
\hline $\begin{array}{l}\text { What are the } \\
\text { incentives for } \\
\text { articulating design } \\
\text { issues? }\end{array}$ & $\begin{array}{l}\text { How is } \\
\text { knowledge } \\
\text { formalized and } \\
\text { packaged? }\end{array}$ & $\begin{array}{l}\text { How is the } \\
\text { knowledge } \\
\text { explicated and } \\
\text { consolidated? }\end{array}$ & $\begin{array}{l}\text { What types of } \\
\text { mechanisms } \\
\text { direct and target } \\
\text { the knowledge? }\end{array}$ & $\begin{array}{l}\text { To what extent is } \\
\text { the knowledge } \\
\text { understandable and } \\
\text { usable for the } \\
\text { designers? }\end{array}$ & $\begin{array}{l}\text { Are there factors } \\
\text { that enable and } \\
\text { motivate } \\
\text { knowledge } \\
\text { integration? }\end{array}$ \\
\hline $\begin{array}{l}\text { Are there enablers } \\
\text { to knowledge } \\
\text { creation? }\end{array}$ & $\begin{array}{l}\text { To what degree } \\
\text { is the captured } \\
\text { knowledge } \\
\text { design oriented? }\end{array}$ & $\begin{array}{l}\text { What kinds of } \\
\text { filters are } \\
\text { applied to the } \\
\text { captured } \\
\text { knowledge? }\end{array}$ & $\begin{array}{l}\text { Who are the } \\
\text { senders and } \\
\text { receivers and how } \\
\text { do they } \\
\text { communicate? }\end{array}$ & $\begin{array}{l}\text { To what extent is } \\
\text { operational } \\
\text { knowledge } \\
\text { translated and } \\
\text { interpreted in } \\
\text { different ways? }\end{array}$ & $\begin{array}{l}\text { What are the } \\
\text { incentives to apply } \\
\text { operational } \\
\text { knowledge in the } \\
\text { design process? }\end{array}$ \\
\hline $\begin{array}{l}\text { What are the key } \\
\text { performance } \\
\text { indicators (KPIs)? }\end{array}$ & $\begin{array}{l}\text { Is it encouraged } \\
\text { to register and } \\
\text { share design- } \\
\text { oriented } \\
\text { knowledge? }\end{array}$ & $\begin{array}{l}\text { How is the } \\
\text { knowledge } \\
\text { processed in the } \\
\text { KT system? }\end{array}$ & $\begin{array}{l}\text { Are people also } \\
\text { channels of } \\
\text { dissemination as } \\
\text { part of the KT } \\
\text { process? }\end{array}$ & $\begin{array}{l}\text { Are there } \\
\text { procedures for } \\
\text { continuously } \\
\text { integrating } \\
\text { operational } \\
\text { knowledge into } \\
\text { standard design } \\
\text { phases? }\end{array}$ & What are the KPIs? \\
\hline
\end{tabular}

\section{Discussion}

The need for and benefits of transferring operational knowledge and experiences to the engineering design of new work systems have been touched upon in the literature. However, there are gaps in our understanding of the KT process itself. We have addressed this gap by developing a conceptual model to better understand the processes involved in this type of KT. We concluded by applying the model in a case company to identify key challenges and by developing a diagnostic tool for a KT system for use within offshore and maritime companies.

The KT in this context requires knowledge to be captured on operating units, transformed into an engineering design context, transferred to the appropriate project team members, and finally, applied at the appropriate time during the design process for new units. These steps in the KT process included in the four-step model we developed are in line 
with the idealized model presented in Figure 1. In this model, Kjellén (2007) also addressed four steps: 1) the knowledge databases are generated in the capture step, 2) the documents as knowledge carriers are formulated during the transformation step, 3) the arenas for knowledge exchange are part of knowledge circulation during the transfer step, and 4) the design process itself is where the designers will take in and use the knowledge transferred during the application step. Our main contribution was to structure the KT process in a way that the related challenges can be also structured within the steps of the process, making it easier to identify and bridge the existing gaps. Our model also formalize and add some important activities to the KT process: the capture of knowledge itself, the transformation of this knowledge, and the contextualization of both sender and receiver by introducing the work systems concepts.

The challenges existing within each of these steps of the KT process became clear during the case study. There is motivation on both sides to have operational knowledge transferred to design, but there is a lack of methods and tools that allow the appropriate knowledge to arrive at the right time and be retrieved by the right people. Some of the challenges are in line with what has been identified in other studies as well, such as the challenge of retrieving relevant operational knowledge from the formal systems, leading to the use of personal strategies and informal means to retrieve this knowledge (Ahmed-Kristensen and Vianello, 2015; Vianello and Ahmed, 2012) and the challenge of encouraging operational personnel to engage in the KT process (Ranjbarfard et al., 2014). The recurrent challenges of information overload and huge amounts of documentation have also been highlighted in different studies (Lurås et al., 2015; Wold and Laumann, 2015; Wulff et al., 2000). This challenge is related to some of the other challenges we identified, such as the need to qualify and filter captured operational knowledge and the difficulties of integrating this knowledge into the projects at the right time. The entire process requires a continuous flow to develop a permanent repository that is continuously updated and used to optimize the design of new units.

Table 4 shows the correspondence of the challenges found in the literature with the challenges made clear in our study, all structured according with the four-step model. Most challenges are in line with each other. Our main contributions are 1) to structure these challenges within the steps of the KT process and 2) to give more details for the understanding of these challenges than in previous studies. In the capturing step, for example, previous studies relate to obstacles to gaining user insight. In our study, we specify some of these obstacles, such as captured knowledge not being targeted or oriented toward design and different systems being used for capturing and retrieving the knowledge. With more details on which obstacles are present in the process, and where is the KT process they happen, help targeting the diagnosis and possible solutions to improve the KT. 
Table 4 Knowledge transfer (KT) challenges from previous studies versus the challenges we identified in our study.

\begin{tabular}{|c|c|c|}
\hline KT Steps & Challenges from Literature & Challenges Identified with Our Study \\
\hline \multirow{3}{*}{ Capturing } & \multirow{2}{*}{ Obstacles to gaining user insight } & Captured knowledge is not targeted or oriented toward design \\
\hline & & Different systems for capturing and retrieving knowledge are used \\
\hline & $\begin{array}{l}\text { Lack of alignment between critical } \\
\text { knowledge and organizational goals }\end{array}$ & $\begin{array}{l}\text { Key performance indicators do not encourage knowledge capture or } \\
\text { transfer for design purposes }\end{array}$ \\
\hline \multirow{3}{*}{ Transforming } & $\begin{array}{l}\text { Vague descriptions and fragmented } \\
\text { knowledge }\end{array}$ & $\begin{array}{l}\text { Difficult to qualify captured knowledge due to the amount and } \\
\text { complexity }\end{array}$ \\
\hline & \multirow{2}{*}{$\begin{array}{l}\text { Lack of translating, filtering, and } \\
\text { structuring knowledge to address } \\
\text { designers' needs }\end{array}$} & Captured knowledge is not transformed for target design activities \\
\hline & & $\begin{array}{l}\text { Systems are not configured to transform captured knowledge for use } \\
\text { in design processes }\end{array}$ \\
\hline \multirow{3}{*}{ Transferring } & \multirow{2}{*}{$\begin{array}{l}\text { Lack of systematic transfer and } \\
\text { technical support on knowledge } \\
\text { management tools }\end{array}$} & $\begin{array}{l}\text { Lack of systems or management strategies for bringing operational } \\
\text { knowledge into the design process }\end{array}$ \\
\hline & & $\begin{array}{l}\text { Difficult for the design team to search for and retrieve relevant } \\
\text { knowledge }\end{array}$ \\
\hline & $\begin{array}{l}\text { Lack of appropriate structure for } \\
\text { bringing workers into the transfer } \\
\text { process }\end{array}$ & Transfer of knowledge relies on individuals and personal strategies \\
\hline \multirow{3}{*}{ Applying } & Information overload & $\begin{array}{l}\text { Difficult to integrate operational knowledge into design projects at } \\
\text { the right time }\end{array}$ \\
\hline & \multirow{2}{*}{$\begin{array}{l}\text { Operational knowledge pushed into } \\
\text { systems but not used during design }\end{array}$} & $\begin{array}{l}\text { Interaction with external actors may limit the possibility of including } \\
\text { operational knowledge }\end{array}$ \\
\hline & & $\begin{array}{l}\text { No formal transfer of learnings and experiences from project to } \\
\text { project }\end{array}$ \\
\hline
\end{tabular}

The conceptual model complements the study by Vianello and Ahmed (2012) in specifying that KT entails several processes, each of which has its own challenges that influence the overall outcome. We have also addressed the obstacles to knowledge management pointed out by Ranjbarfard et al. (2014). By including the work systems in the conceptual model, we have been able to emphasize the importance of organizational factors in improving KT. The focus is on bringing the KT issue into the strategic level of a company and on the KT capacities of the operations and engineering design work systems (Parent et al., 2007).

\subsection{Effects for Practitioners}

The conceptual model provides knowledge management and engineering design professionals in the offshore and maritime industries with an overview of the processes involved in KT from operations at sea to engineering design projects onshore. With the help of the diagnostic tool, such professionals can map and specify the current situation and identify the parts of the process in which challenges can be found. This allows for better understanding of design problems to be faced and for developing design solutions that improve health, safety, and production effectiveness.

\subsection{Limitations}

This study is based on the literature and on empirical insight gained from a single offshore oil company case study. The proposed KT model seems to be generalizable to the maritime industry and possibly to other industries as well. However, more studies within the maritime industry are needed to consolidate the model and fill out the details. Such research would also make it possible to flesh out the diagnostic tool, making it more useful for professionals within the industry. 


\subsection{Further Research}

From a research point of view, the conceptual model should be tested on several industrial cases to validate its comprehensiveness. Is the model able to grasp the most important steps in KT? Does the model help identify theoretical challenges in understanding the process of transferring knowledge between operations and engineering design? We also see a potential development of the model into a maturity grid with possibilities for scoring each question and thus improving the diagnostic capabilities. Furthermore, additional research is needed to determine which KT formats are the best for bringing operational knowledge into engineering design projects.

\section{Conclusion}

We have developed a conceptual model of KT from operations to engineering design by connecting two areas of research. By introducing the work system model, we were able to specify how to handle the contexts of both the sender and the receiver in KT. By modeling the KT process in four steps, we were able to structure and better comprehend the key challenges involved. The four-step CTTA model supports the systematic framing of the KT process, allowing for comparison between different cases to generalize the findings. In contrast to other KT models, we stress the importance of transferring as much of the specific operational context as possible to the engineering design. This is of significance for engineering designers, as they need to understand the problem to design better solutions on new rigs to optimize costs, system performance, health, and safety.

\section{Acknowledgment}

Funding: This work was supported by the Danish Maritime Fund [Grant \# 2014-020].

\section{References}

Ahmed-Kristensen, S., \& Vianello, G. (2014). A model for reusing service knowledge based on an empirical case. Research in Engineering Design, 26(1), 57-76. https://doi.org/10.1007/s00163-014-0184-6

Alter, S. (2008). Defining information systems as work systems: implications for the IS field. European Journal of Information Systems, 17(5), 448-469. https://doi.org/10.1057/ejis.2008.37

Alter, S. (2010). Including Work System Co-Existence, Alignment , and Coordination in Systems Analysis and Design. 16th Americas Conference on Information Systems, (August), 1-9.

Brooks, J., McCluskey, S., Turley, E., \& King, N. (2015). The utility of template analysis in qualitative psychology research. Qualitative Research in Psychology, 12(2), 202-222. https://doi.org/10.1080/14780887.2014.955224

Conceição, C., Silva, G., Broberg, O., \& Duarte, F. (2012). Intermediary objects in the workspace design process: Means of experience transfer in the offshore sector. Work, 41, 127-135. https://doi.org/10.3233/WOR-20120146-127

Dixon, N. M. (2000). Common Knowledge: How Companies Thrive by Sharing What They Know (1st ed.). Boston: Harvard Business School Press.

Frank, A. G., \& Ribeiro, J. L. D. (2014). An integrative model for knowledge transfer between new product development project teams. Knowledge Management Research \& Practice, 12(2), 215-225. https://doi.org/10.1057/kmrp.2012.57

Hale, A., Kirwan, B., \& Kjellén, U. (2007). Safe by design: where are we now? Safety Science, 45(1-2), 305-327. https://doi.org/10.1016/j.ssci.2006.08.007 
Hansen, M. T., Nohria, N., \& Tierney, T. (1999). What's your strategy for managing knowledge? Harvard Business Review, 77(2), 106-116.

Hicks, B. J., Culley, S. J., Allen, R. D., \& Mullineux, G. (2002). A framework for the requirements of capturing, storing and reusing information and knowledge in engineering design. International Journal of Information Management, 22(4), 263-280. https://doi.org/10.1016/S0268-4012(02)00012-9

Horgen, T., Joroff, M. L., Porter, W. L., \& Schön, D. A. (1999). Excellence By Design: Transforming Workplace and Work Practice (1st ed.). New York: John Wiley \& Sons.

Johnsen, S. O. (2014). (Why) Are cognitive human factors missing from the blunt end in the oil and gas industry? Human Factors in Organizational Design and Management - Xi Nordic Ergonomics Society Annual Conference - 46, 699(June), 699-704.

Kjellén, U. (2007). Safety in the design of offshore platforms: Integrated safety versus safety as an add-on characteristic. Safety Science, 45(1-2), 107-127. https://doi.org/10.1016/j.ssci.2006.08.012

Lurås, S., Lützhöft, M., \& Sevaldson, B. (2015). Meeting the complex and unfamiliar: Lessons from design in the offshore industry. International Journal of Design, 9(2), 141-154.

Mallam, S. C., Lundh, M., MacKinnon, S. N. (2015). Integrating human factors \& ergonomics in large-scale engineering projects: Investigating a practical approach for ship design. International Journal of Industrial Ergonomics, 50, 62-72. https://doi.org/10.1016/j.ergon.2015.09.007

McMahon, C., Lowe, A., \& Culley, S. (2004). Knowledge management in engineering design: Personalization and codification. Journal of Engineering Design, 15(4), 307-325. https://doi.org/10.1080/09544820410001697154

Mougin, J., Boujut, J. F., Pourroy, F., \& Poussier, G. (2015). Modelling knowledge transfer: A knowledge dynamics perspective. Concurrent Engineering, 23(4), 308-319. https://doi.org/10.1177/1063293X15592185

Nesheim, T., \& Gressgård, L. J. (2014). Knowledge sharing in a complex organization: Antecedents and safety effects. Safety Science, 62, 28-36. https://doi.org/10.1016/j.ssci.2013.07.018

Pagenhart, A., Buset, H., \& Throndsen, T. I. (1998). Experience Transfer from Operational Environments to Installation Design: Why, How. In SPE International Conference on Health, Safety, and Environment in Oil and Gas Exploration and Production. Caracas: Society of Petroleum Engineers. https://doi.org/10.2118/48828MS

Parent, R., Roy, M., \& St-Jacques, D. (2007). A systems-based dynamic knowledge transfer capacity model. Journal of Knowledge Management, 11(6), 81-93. https://doi.org/10.1108/13673270710832181

Ranjbarfard, M., Aghdasi, M., López-Sáez, P., \& Emilio Navas López, J. (2014). The barriers of knowledge generation, storage, distribution and application that impede learning in gas and petroleum companies. Journal of Knowledge Management, 18(3), 494-522. https://doi.org/10.1108/JKM-08-2013-0324

Shannon, C. E. (1948). A mathematical theory of communication. The Bell System Technical Journal, 27(July 1928), 379-423. https://doi.org/10.1145/584091.584093

Skepper, N., Straker, L., \& Pollock, C. (2000). A case study of the use of ergonomics information in a heavy engineering design process. International Journal of Industrial Ergonomics, 26(3), 425-435. https://doi.org/10.1016/S0169-8141(00)00017-2

Taylor, J. R. (2007). Understanding and combating design error in process plant design. Safety Science, 45(1-2), 75105. https://doi.org/10.1016/j.ssci.2006.08.014

Vianello, G., \& Ahmed, S. (2012). Transfer of knowledge from the service phase: A case study from the oil industry. 
Research in Engineering Design, 23(2), 125-139. https://doi.org/10.1007/s00163-011-0118-5

Walker, G. H., Waterfield, S., \& Thompson P. (2014). All at sea: An ergonomic analysis of oil production platform control rooms. International Journal of Industrial Ergonomics, 44(5), 723-731. https://doi.org/10.1016/j.ergon.2014.08.001

Wold, T., \& Laumann, K. (2015). Safety Management Systems as communication in an oil and gas producing company. Safety Science, 72, 23-30. https://doi.org/10.1016/j.ssci.2014.08.004

Wulff, I. A., Rasmussen, B., \& Westgaard, R. H. (2000). Documentation in large-scale engineering design: Information processing and defensive mechanisms to generate information overload. International Journal of Industrial Ergonomics, 25(3), 295-310. https://doi.org/10.1016/S0169-8141(99)00020-7

Wulff, I. A., Westgaard, R. H., \& Rasmussen, B. (1999a). Ergonomic criteria in large-scale engineering design - I: Management by documentation only? Formal organization vs. designers’ perceptions. Applied Ergonomics, 30(3), 191-205. https://doi.org/10.1016/S0003-6870(98)00029-5

Wulff, I. A., Westgaard, R. H., \& Rasmussen, B. (1999b). Ergonomic criteria in large-scale engineering design - II: Evaluating and applying requirements in the real world of design. Applied Ergonomics, 30(3), 207-221. https://doi.org/10.1016/S0003-6870(98)00030-1

Yakhlef, A. (2007). Knowledge transfer as the transformation of context. Journal of High Technology Management Research, 18(1), 43-57. https://doi.org/10.1016/j.hitech.2007.03.003 